\title{
An intermediate standard of proof in serious civil cases in England and Wales
}

SHAMINI K RAGAVAN

University of Newcastle

Keywords: Civil justice; evidence; standard of proof; intermediate standard of proof

\section{Introduction}

For over half a century, judges have spoken in imprecise terms of a standard of proof in civil cases involving serious allegations or bearing a serious consequence (serious civil cases), a standard higher than the 'balance of probabilities' (see Bater v Bater). Judges have continued to explain and define the standard of proof in serious civil cases across pages and pages of their judgments and continue to adopt various approaches since the early twentieth century. The vagueness of these explanations is far from coherent. The true scope of the case law on the civil standard in serious civil cases remains confusing and subsequent case law has not settled into a clear path, despite precedent established in the House of Lords in $\operatorname{Re} B$ and $\operatorname{Re} D$. In the interests of greater certainty and consistency, this paper seeks to offer a better approach - a third standard of proof, a standard lying between the ordinary civil standard of balance of probabilities and the higher criminal standard of beyond reasonable doubt. ${ }^{1}$ This 'third-standard' approach would be open-textured, but it would be stabilised by identifying a range of clear cases to which it could be applied. New serious civil cases could be embraced by the third standard if, and only if, a suitably strong analogical argument could be devised. This approach would set in motion a process of incremental development and would, thus, by nature be a source of some uncertainty. However, it would be clearer than the law as it now stands and mark a significant advance over the imprecision that has prevailed for too long.

This paper will first address how the courts approach a typical civil case and a serious civil case. In a typical civil case (e.g. a commercial or negligence action), the balance of probabilities standard is applied. This is because society has a minimal concern with the outcome of such private suits, and monetary redress is typically in the ultimate interest of the claimant. Parties in a civil case share the risk of error equally. ${ }^{2}$ This means that as long

* I am grateful to the anonymous reviewers for their comments. I would like to also thank Richard Collier, Ian Dawson, Richard Mullender and Ashley Wilton for their comments on earlier drafts of this paper. An earlier version of this paper was delivered at the Newcastle Law School Developmental Workshop, 21 May 2012.

1 R v Hepworth [1955] 2 QB 600 per Lord Goddard CJ: 'One would be on safe ground if one said in a criminal case to a jury: "You must be satisfied beyond reasonable doubt". One could also say - "You, the jury, must be completely satisfied" - or, better still - "You must feel sure of the prisoner's guilt".'

2 One function of legal process is to minimise the risk of erroneous decisions. 
as the balance of probabilities is met, the typical case is decided in favour of the party that tilts the scale to a degree of more than 0.5 or 50 per cent. ${ }^{3}$ Similarly, the term 'balance of probabilities' is defined as to 'think it more probable than not that an event had occurred.' 4 This implies that, if the probabilities of occurrence and non-occurrence are equal, the event is then deemed to have not occurred.

Serious civil cases are quite different and take many forms. They may involve a criminal accusation; for example, an allegation of arson in an action on insurance policy, ${ }^{5}$ or that of murder in a probate proceeding. ${ }^{6}$ Such accusations may lead to the removal of a child from the family home on grounds of abuse, ${ }^{7}$ or result in issues affecting liberty and livelihood, such as the deportation of a person back to his/her country of origin, ${ }^{8}$ or declining to recommend the release of a prisoner. ${ }^{9}$ More often than not, serious civil cases go beyond financial loss. Such cases seem to indicate that the degree or cogency of the evidence required by the individual case depends very much on the nature of the serious allegation and its consequence, if proved true in the civil court. Whether the nature or consequence of the case is serious, in this paper both are referred to as serious civil cases. The general approach when confronted with a serious civil case is for the judge to apply an approach implying some 'deviation' from the normal balance of probabilities. In Issais, ${ }^{10}$ for example, the court stated that a civil case concerned with an allegation of arson cannot be considered to require the same standard of proof as a commercial action or one related to negligence. Lord Atkin relied on several authorities ${ }^{11}$ and stated that if the commission of a crime is directly in issue in any proceeding, criminal or civil, it must be proved beyond reasonable doubt'. ${ }^{12}$ This raises the need for a separate standard.

Thus, the question is what course, away from the normal approach, should be taken in serious civil cases? The answer is that the deviation is typically a further step taken by the judge to ensure that the evidence produced by the party alleging a serious issue is cogent and commensurate to the seriousness of the allegation and/or its consequence. ${ }^{13}$ The confusion in this further step stems from the 'remodelling' of the balance of probabilities standard to extend its application to serious civil cases, as well as the fact that the choice of

3 Lord Denning in Miller v Minister of Pensions [1947] 2 All ER 372, 373-74, gave one of the clearest explanations of what amounts to the civil standard of proof. For the sake of convenience, a mathematical quantification is used to explain the operation of a typical civil case: to win a civil case, the claimant need only prove probability to a degree of more than 0.5: C M A McCauliff, 'Burdens of Proof: Degrees of Belief, Quanta of Evidence, or Constitutional Guarantees?’ (1982) 35 Vanderbilt Law Review 1293-335. See also Mike Redmayne in 'Standards of Proof in Civil Litigation' (1990) 62(2) MLR 167-74. He defends the 0.5 rule adequately from the perspectives of expected utility of verdict, minimising expected errors, and treatment of symmetry for both the claimant and the defendant in a civil case. Moreover, the word 'balance' is indicative of equi-probability between the claimant and the defendant, and some may argue this to be a weakness. See David Hamer, 'Probabilistic Standards of Proof, their Complements and the Errors that are Expected to Flow from Them' (2004) 1(1) UNELJ 71.

4 Denning LG in Miller v Minister of Pensions (n 3).

5 Issais v Marine Insurance Co Ltd [1923] 15 LI L Rep 186.

6 Re Dellow's Will Trusts [1964] 1 WLR 451.

$7 \quad \mathrm{Re} B$ [2009] 1 AC 11.

8 Al-Khawaja v Secretary of State for the Home Office [1984] AC 74.

9 Re D [2008] 1 WLR 1499.

10 Issais (n 5) 192.

11 John Pitt Taylor and G Pitt-Lewis, A Treatise on the Law of Evidence as Administered in England and Ireland: With Illustrations from Scotch, Indian, American and Other Legal Systems (9th edn Sweet \& Maxwell 1895); and James F Stephen, A Digest of the Law of Evidence (MacMillan \& Co 1876).

12 Issais (n 5) 192.

13 Various serious civil cases have applied this approach and a more in-depth discussion can be found in section 1 below. 
language used lacks clarity. Unfortunately, the exact nature of this further step and what it entails is not always clear, as various approaches and interpretations have been applied by judges in the past.

Two notable approaches have emerged from this deviation: the 'flexible' and the 'prior probability' approaches that have been consistently applied since the 1950s (these will be discussed in detail in section 1 below). This remodelling of the civil standard to apply in serious civil cases is a departure from the traditional understanding of the civil standard of proof. It is argued in this paper that, by incorporating an additional step in serious civil cases, when the same is not required in a typical civil case, a different standard is effectively being applied. It is also argued in this paper that, when such words are used (i.e. cogent evidence commensurate with the gravity of the allegation) and further careful scrutiny of the evidence is presented in serious civil cases, the purpose is not merely to prove with a balance of probabilities that the event has taken place, but to persuade the fact-finder that the event has actually taken place (persuade mandates something more than mere probabilistic proof of the occurrence or existence of the fact). The language used by judges in the cases discussed in section 1 below demonstrates this purpose.

It is argued that, to achieve this purpose, the standard ought to be a higher standard of the balance of probabilities and distinct from the civil standard (i.e. at least 51 per cent). Judges cannot expect cogent evidence and at the same time state that the standard is the civil standard of probabilities. This approach breaches the principle of non-contradiction by asserting 'P' and 'Not-P' simultaneously (which is logically unsustainable). A case for a higher standard of proof is, thus, made and better known as the intermediate standard of proof, which can be seen in America (see section 3). ${ }^{14}$

The definitions of both the standard of proof and the civil standard of balance of probabilities become essential to this discussion. Standard of proof is defined as 'the degree [emphasis added] of cogency or persuasiveness required of the evidence adduced by a party, in order to discharge a burden of proof borne by the said party'. ${ }^{15}$ The definition explicitly states that it is the degree of cogency or weight of the evidence that determines whether the standard has been met. If this is the case, then it is difficult to rationalise how mandating more cogent evidence would not affect the degree of proof.

Standards of proof are placed based on this determination - the more serious the case, the higher the standard of proof; the less serious the case, a lower standard is applied. Thus, when a case involves serious issues, how does the standard of proof protect against errors? Typically, the standard of proof applicable is determined by the extent to which the finding affects the party whose allegation has been proved true. This ought to create an awareness that the finding that the allegation is true would mean the finding would affect the party the allegation is made against. ${ }^{16}$ Similarly, the level at which a standard is set is a key determinant of the type of error that may occur. The appreciation that the expected number of errors in a serious civil case increases as a result of the fact-finding process based on the seriousness of the allegation made and the consequence of the allegation, affects the standard of proof: a similar appreciation is that the expected number of errors

14 See Denning LJ, Miller v Minister of Pensions (n 3). See also, Rosemary Pattenden, 'The Risk of Non-persuasion in Civil Trials: The Case Against a Floating Standard of Proof' (1988) (7) CJQ 220 -33, which states that either terminology is confusing, in that 'probabilities' means both parties are in equilibrium, when this is not the case. The latter, on the other hand, seems to suggest the cogency, rather than the quality, of the evidence.

15 Miller $v$ Minister of Pensions (n 3).

16 Redmayne (n 3) 169 suggests that the choice of the appropriate standard comes from the 'expected consequences of our fact-finding decisions'. He stated that the reason the criminal standard is much higher is due to the awareness of the possible consequence in the event the defendant is found guilty. 
in a typical civil case is lower than in serious civil cases, hence the standard is the lower standard of balance of probabilities. The closer that a fact-finder is able to get to certainty, the greater the opportunity of avoiding error. And this is argued to be the underlying reason for the various approaches and interpretations in serious civil cases (see discussion in section 1 below) - the need to achieve greater certainty in these cases. If this is the case, then a higher standard ought to be imposed as opposed to the balance of probabilities. The use of an intermediate standard would serve to protect the party accused of a serious allegation against any mistakes made by the fact-finder against the cost of potential errors made in the adjudication of that particular case.

In section 1, the hierarchy of serious civil cases in the UK is described, explaining how the adoption of varying approaches of the civil standard of balance of probabilities in these cases is unsatisfactory. This paper then provides an explanation of why the different language used causes incoherence and indicates a different (and often higher) standard of proof compared to the balance of probabilities standard. In section 2, an explanation is provided as to why the intermediate standard of proof ought to be used in serious civil cases, drawing similarities to certain 'special civil cases'. The use of such a standard is considered in America in section 3. This paper then explores, in section 4, the reluctance of the judges to adopt an intermediate standard of proof and reasons underlying their reluctance, and section 5 outlines possible reform in serious civil cases.

\section{Serious civil cases in England and Wales}

\section{(A) THE EARLY CASES}

In early cases, attempts were made to address the presence of a serious allegation in a civil case by applying the criminal standard of proof. This is evident, in particular, in divorce proceedings based on grounds of adultery ${ }^{17}$ and cruelty, ${ }^{18}$ prior to the Divorce Reform Act 1969. The criminal standard of proof was also applied in legitimacy ${ }^{19}$ and professional misconduct cases. ${ }^{20}$ The primary reason as to why the criminal standard had been applied in the cases above is the seriousness of the allegation and its consequences. Some judges have gone on to say that the distinction between the criminal and civil standard is clargely illusory'. ${ }^{21}$ However, none of these cases has suggested the intermediate standard of proof approach as applied in America. ${ }^{22}$ As it appears, the controversy on the appropriate

17 Various dicta are found in Ginesi v Ginesi [1948] P 179; Bastable v Bastable and Sanders [1968] 1 WLR 1684. At the time, adultery was regarded as a quasi-criminal offence by the ecclesiastical courts.

18 Bater v Bater [1951] P 35; Davis v Davis [1950] P 125. The criminal standard was, perhaps, more readily understandable prior to the Divorce Reform Act 1969, since the grounds for divorce were at that time still depicted as matters of proving fault.

19 See Preston-Jones v Preston-Jones [1951] AC 39. In Serio v Serio [1983] 4 FLR 756, the Court of Appeal did not apply s 26 of the Divorce Reform Act 1969 when it came to rebutting the presumption of legitimacy and stated that the standard could not just be the civil standard, but rather a higher standard.

$20 \operatorname{Re}$ A Solicitor [1992] QB 69.

21 See Lord Bingham in his dictum in B v Chief Constable of Avon and Somerset Constabulary [2001] 1 WLR 340, 353-54 [31]; Lord Scarman in Al-Khawaja (n 8) 113-14 stated that the degree of probability must be such that the court is satisfied; Lord Goddard in Rv Hepworth and Fearnley [1955] 2 QB 600, 603, where he stated that he was unable to understand the difference between the criminal and civil standards of proof. Compare this to $\operatorname{Re} W$ (Minors) [1994] 1 FLR 419, 426, where Balcombe J stated that the trial judge should have applied the higher standard of proof, instead of the basic civil standard of proof (on appeal, however, the Court of Appeal emphasised that the standard is the balance of probabilities). Similarly, Lord Bingham CJ in the Court of Appeal in R (McCann) v Crown Court at Manchester [2003] 1 AC 787 commented that the heightened civil standard and the criminal standard are virtually indistinguishable.

22 For the explanation of the term 'clear and convincing' evidence, see Charles T McCormick, McCormick on Evidence (5th edn West Publishing 1999) ch 36, 340. A more detailed discussion is found in section 3 below. 
standard of proof that ought to apply in serious civil cases emerged even before Bater $v$ Bater or Hornal $v$ Neuberger Products $L t d^{23}$ were decided.

Alongside the early cases, an alternative strand emerged, including that seen in Bater $v$ Bater 24 and Hornal $v$ Neuberger Products Ltd. ${ }^{25}$ For example, Denning LJ in Bater v Bater propounded a floating standard of proof in serious civil cases, which depended largely on the subject matter of the allegation. Although the standard introduced is variable (i.e. flexible), it is not as high as the criminal standard: ${ }^{26}$

Many great judges have said that, in proportion as the crime is enormous, so ought the proof to be clear. The case may be proved by a preponderance of probability, but there may be degrees of probability within that standard. ${ }^{27}$

The standard propounded in Bater $v$ Bater is indeterminate and there is an absence of meaning. This is overstated as a criticism, since the relevant standard is known to exceed 0.5. It could, perhaps, be lower than the criminal standard; this is, however, vague. It might be said with more justification that the Bater approach exhibits a lack of clear meaning, which means that the Bater approach opens up a field of interpretative possibility. This field occupies the space between the civil standard and the (not precisely expressed) criminal standard. Similar ambiguity is observed in Hornal $v$ Neuberger 28 and Re Dellow's Will Trusts ${ }^{29}$ below.

In Hornal $v$ Neuberger, Lord Morris, obiter (together with Lord Hobson) said that 'the very elements of gravity become a part of the whole range of circumstances which have to be weighed in the scale when deciding as to the balance of probabilities' ${ }^{30}$ After citing Lord Morris in Hornal, Ungoed-Thomas J in Re Dellow's Will Trusts, where the issue was whether a wife feloniously had killed her husband, upheld that: 'The more serious the allegation the more cogent is the evidence required to overcome the unlikelihood of what is alleged and thus to prove it. ${ }^{31}$ The court saw this as a serious issue based on the facts that if the case is proved, the wife will be branded a murderer. ${ }^{32}$

\section{(B) The law today: from Re $H$ to Re $B$ and Re $D$}

The law as it stands today can be derived from Lord Nicholls' statement in Re H (see below) that mandating stronger evidence in serious civil cases does not affect the standard of balance of probabilities: ${ }^{33}$

the court will have in mind as a factor, to whatever extent is appropriate in the particular case [emphasis added], that the more serious the allegation the less likely it is that the event occurred and, hence, the stronger should be the evidence before the

23 [1956] 3 All ER 970.

24 [1950] 2 All ER 458; approved in Blyth v Blyth [1966] AC 643 and endorsed in Al-Khawaja (n 8).

25 Hornal v Neuberger [1957] 1 QB 247.

26 Redmayne referred to the approach in Bater as the flexible standard, whereby the standard of proof varies according to the seriousness of the issues (n 3) 181-84.

27 Bater (n 18) 459.

28 Hornal v Neuberger (n 25).

29 See Re Dellow's Will Trusts (n 6).

30 Hornal v Neuberger (n 25) 978.

31 Re Dellow's Will Trusts (n 6) 455; see also Redmayne (n 3) 184-87 who refers to this as the 'prior probability' approach.

32 The same reasoning was found in the Australian case of Helton v Allen [1940] 63 CLR 691 (HC).

33 Lord Nicholls in Re H (Minors) (Sexual Abuse: Standard of Proof) [1996] AC 563, 586. This passage by Lord Hoffmann, in $\operatorname{Re} B$ (n 7) 6, reiterates Lord Nicholls' view in Re H. 
court concludes that the allegation is established on the balance of probabilities. ${ }^{34}$

Lord Hoffmann in Re B focused on the words italicised above in Lord Nicholls' passage in $\mathrm{Re} H$ and stated that $\mathrm{Re} H$ did not lay down any rule of law, but merely states that when there is a serious allegation, one needs to use common sense and not law to determine if the occurrence of a fact in issue had been proved on a balance of probabilities. ${ }^{35}$ Lord Hoffmann went further to explain how the inherent probabilities test operates by providing the example of a child alleging sexual abuse by a parent, and how it is common sense to start with the assumption that most parents do not abuse their children, but that this assumption may be dispelled by adducing compelling evidence of the relationship between the parent and the child. He also stated that:

it would be absurd to suggest that the tribunal must in all cases assume that
serious conduct is unlikely to have occurred. In many cases, the other evidence
will show that it was all too likely. The fact that the child was assaulted by one of
the two people, that it would make no sense to start one's reasoning by saying
that assaulting children is a serious matter and therefore neither of them is likely
to have done so. ${ }^{36}$

It is submitted that Lord Hoffmann's explanation of how the balance of probabilities test works in the example given above is indeed incomprehensible. Fact-finders do take notice of the seriousness of the allegation and the consequence of the allegation as a whole before it is proven in court, and this is often taken into consideration against the evidence presented in court when deciding if the occurrence of a fact in issue has taken place or not. Typically, the issue of likelihood and unlikelihood of the fact is something the party bringing the action must prove in court. So, in the example provided by Lord Hoffmann above, the party bringing the action would need to bring compelling evidence to prove the allegation of sexual abuse has been made; and, often, the party bringing the action already has in mind who the perpetrator is and will present the case with that perpetrator in mind. Following Lord Hoffmann's explanation above, his Lordship seems to be dissecting the facts and showing how the initial stage of proving sexual abuse places a greater responsibility on the part of the party bringing the action to prove that sexual abuse had indeed taken place. What if the identity of the perpetrator is in issue? For example, what if the mother had various partners during the time the child was abused? Would there not be a need for compelling evidence to identify the perpetrator and not just establish that the event did in fact occur?

Lord Hoffmann in Re B further stated that the inherent probabilities and the gravity of the allegation are not related. ${ }^{37}$ It is argued in this paper that the very use of the inherent probabilities approach to certain cases that are deemed serious can only mean that the seriousness of the case (or the gravity of the allegation) warrants careful consideration on the evidence received in court. When this is the case, it is difficult to comprehend Lord Hoffmann's perception that inherent probabilities and the gravity of the allegation are not related.

A more recent case, $R e D$, involved the decision of the Life Sentence Review Commissioners in Northern Ireland not to direct release from prison (on licence) of D,

34 Re H (n 33) 586 approves Hornal v Neuberger (n 25) and Re Dellow's WT (n 6). Consistently with Lord Hoffmann, Baroness Hale in the same case held that neither the seriousness of the allegation nor the consequences affect the standard of proof, therefore inherent probability should be considered, where relevant, in deciding where the truth lies.

$35 \operatorname{Re} B(\mathrm{n} 7) 21$.

36 Ibid.

37 Ibid. 
who was serving a life sentence for murder, on the basis of protecting the public from D and confining him to further sentence despite completing the 'tariff' part of his sentence. ${ }^{38}$ Lord Carswell in $\mathrm{Re} D,{ }^{39}$ expounded that, in some contexts, the courts need to look at the facts 'more critically or anxiously' and apply good sense before the civil standard is satisfied, in particular in cases that involve a serious allegation or bear a serious outcome. ${ }^{40}$ This approach is the 'anxious scrutiny' test. This test, explained in $\operatorname{Re} D$, suggests that judges apply caution when weighing evidence in a serious civil case. ${ }^{41}$ However, in $\mathrm{Re} D$, Lord Carswell stated that this did not imply that the case required a different standard or an especially cogent standard of evidence, ${ }^{42}$ suggesting that the balance of probabilities should still be the guiding factor in making the ruling. The issue of using good sense or 'common sense' further contributes to the uncertainty in this area, as Lord Carswell's statement dictates the need for caution in serious civil cases and not a separate, and thus higher, standard of proof. ${ }^{43}$ However, choosing common sense over clear guidance is less than ideal. ${ }^{44}$ If judges consistently emphasise the need for common sense when applying the prior probability approach, then the rationale underlying the need to reiterate this approach repeatedly should be questioned.

\section{(C) Problem with the language used by judges}

Based on the language used in cases ranging from Bater $v$ Bater to $R e H$, the judges are seeking cogent evidence to prove the facts alleged in the individual serious civil cases. $\operatorname{Re} B$, a case involving allocation of parental responsibility for children, decided that the criteria found in s 31(2) of the Children Act 1989 (i.e. whether or not the child in question is suffering, or is likely to suffer, significant harm) require the application of a standard of proof based upon the balance of probabilities. ${ }^{45}$ Baroness Hale in $R e B$, consistently with $\mathrm{Re} H$, opined that in childcare cases, in particular, special care is needed with regard to the seriousness of the purported crime and a decision cannot be based on 'unsubstantiated suspicions. ${ }^{46}$ 'This expression by Baroness Hale is unclear. Does it mean that unlike typical civil cases, serious civil cases warrant a careful deliberation on whether the standard of proof is achieved? It is argued in this paper that no case, whether a serious or a typical civil case, should be or indeed is based on unsubstantiated suspicions. On the other hand,

$38 \operatorname{Re} D(\mathrm{n} 9)$.

39 Ibid 1508-09. Lord Carswell stated that the panel should 'devote the necessary critical attention to the evidence adduced in support of such a serious charge'. His Lordship goes on to say that the evidence 'was clear and cogent and pointed very strongly to the conclusion reached by the panel'.

$40 \operatorname{Re} D(\mathrm{n} 9) 1509$.

41 Ibid.

42 Ibid.

43 Consistent with $\mathrm{Re} H$, Lord Hoffmann in Re B said that: 'There is only one rule of law, namely that the occurrence of the fact in question must be proved to have been more probable than not. Common sense, not law, requires that in deciding this question, regard should be had, to whatever extent appropriate, to inherent probabilities.' Lord Hoffmann, also agreeing with Baroness Hale on how common sense is used in care-order applications, said that: 'If a child alleges sexual abuse by a parent, it is common sense to start with the assumption that most parents do not abuse their children. But this assumption may be swiftly dispelled by other compelling evidence of the relationship between parent and child or parent and other children.': (n 7) 21. Also see Lord Carswell in $\operatorname{Re} D$ (n 9) 1509, who refers to the use of 'good sense' in deciding the gravity of the allegation.

44 Peter Mirfield, 'How Many Standards of Proof Are There?' (2009) LQR 31-38. On page 35, Mirfield stated that $\operatorname{Re} B$ had left 'evidential logic, allied with common sense, in charge of the field'.

45 The House of Lords in $\operatorname{Re} B$ (n 7) also affirmed Re U (A Cbild) [2004] EWCA Civ 567 that the same balance of probabilities standard applied to the welfare considerations found in s 1 of 1989 Act.

$46 \operatorname{Re} B(\mathrm{n} 7) 30$. 
'unsubstantiated suspicions' 47 could also indicate the standard of proof to be a much lower standard from that of balance of probabilities. Hence, the choice of language has created confusion about the standard applied in serious civil cases.

Lord Carswell in $\operatorname{Re} D$ went on to state that the civil standard is 'finite and unvarying', 48 suggesting that situations that make such heightened examination necessary may include the inherent unlikelihood of the occurrence taking place, the seriousness of the allegation to be proved, or, in some cases, the consequences which could follow from acceptance of proof of the relevant fact. ${ }^{49}$ Although Lord Carswell asserted that he was not putting forward a new test, or a new requirement, the problem lies with the wording and the corresponding approaches used in the case. ${ }^{50}$ These have the potential to mislead when interpreting what is truly required to prove a serious civil case. For instance, the Court of Appeal in $\operatorname{Re} D$ expressed that the case at hand required 'more cogent evidence than would be conventionally required' and a 'more compelling quality of evidence'. ${ }^{51}$

Lord Carswell in Re D further referred to and endorsed Richards LJ in R(N) v Mental Health Review Board (Northern Region), 52 where Richards LJ stated that the civil standard of proof is flexible in its approach to the 'strength and quality of the evidence' required for an allegation to be proved on the balance of probabilities, and the degree of probabilities is not affected by this. ${ }^{53}$ Incidentally, this is the same approach applied by Denning LJ in Bater $v$ Bater indicating the standard to be a higher standard than the balance of probabilities. ${ }^{54}$

The language used in the cases discussed above requires judges to be meticulous with the evidence presented in court and to exercise caution when faced with a serious civil case. Further examples of the confusing nature of the language used in various cases are: 'the need for cogent evidence'; or that 'the standard must be commensurate with the gravity of the allegation'; or that 'the more serious the event, the less likely that the event took place'; or that the evidence mandates 'anxious scrutiny' - all seem to suggest a different standard than that of the ordinary civil standard of proof that is applied to a typical civil case. ${ }^{55}$ In $\mathrm{Re} H$, Lord Lloyd warned judges of the dangers of the repeated use of such words and the potential for them to harden into a formula. ${ }^{56}$ For this reason, Lord Lloyd (disagreeing with Lord Nicholls in $\mathrm{Re} H$ ) refused to add any comment explaining the civil standard of balance of probabilities in his judgment in $\mathrm{Re} H$.

In $\mathrm{Re} B$, Lord Hoffmann agreed with Lord Steyn in $\mathrm{McCann}^{57}$ and attempted to clarify the approach in serious civil cases by refusing to use 'colourful' language to elucidate the applicable standard and to only consider the inherent probability test where it is relevant. ${ }^{58}$

47 Ibid 30.

48 His Lordship affirms $R v$ Mental Health Review Board [2006] QB 468, Re D (n 9) 1509.

49 Ibid.

50 Ibid 1507-08.

51 Ibid.

52 Mental Health Review Board (n 48).

$53 \operatorname{Re} D$ (n 9) 1509, referred to Mental Health Review (n 48) [62].

54 Bater v Bater (n 18). See also, Redmayne (n 3) 175-76.

55 Lawrence M Sloan, in 'Judicial Decisions and Linguistic Analysis: Is There a Linguist in the Court?' (1995) 73 Washington ULQ 1069, 1076, attributes that language interpreted by judges is often not how linguists would have interpreted the language. He speaks of the tension between definitional and prototypical views of word meaning in judicial setting. Sloan also states that, in hard cases, the 'ordinary meaning' of the word cannot be used to interpret the word(s) and a decision must be made on the kind of analysis the court should use.

$56 \operatorname{Re} H$ (n 33) 577-78.

57 Lord Steyn, in R (McCann) v Crown Court at Manchester (n 21) 812, stated that clarity of the standard that applies is important.

$58 \operatorname{Re} B(\mathrm{n} 7) 35$. 
His Lordship accepted that the process of elucidating the applicable standard has the potential to cause confusion. 59

\section{(D) TOO MUCH EXPLAINING OF THE STANDARD OF PROOF IN SERIOUS CIVIL CASES SENDS A SIGNAL THAT THE STANDARD IS NOT THE NORMAL BALANCE OF PROBABILITIES}

Despite Lord Hoffmann's attempts to demystify the applicable standard in serious civil cases in $\operatorname{Re} B$, his Lordship still proceeded to echo the inherent probability test found in $\mathrm{Re} H$. This does not, unfortunately, provide a convincing explanation that the standard in serious civil cases is that of the normal balance of probabilities, as the need to remind factfinders of the additional step (approach) in serious civil cases that needs to be undertaken is not often extended to typical civil cases. In this sense, there seems to be an element of fear or anxiousness when judges are faced with serious civil cases, while this is not the case with typical civil cases. ${ }^{60}$

This means that the more serious the accusation, the less it is believed and thus the greater the need for the evidence to convince the judge. The choice of the appropriate standard of proof is determined by the appreciation or awareness of the expected consequences of our fact-finding decisions. ${ }^{61}$ It is argued in this paper that, for the judge to be convinced that the evidence produced by the party to prove the allegation is true, then the cogency (or 'weight') of the evidence becomes significant. For this reason, in serious civil cases, the seriousness of what is alleged or its consequence has a correlation with the weight of the evidence received in court and this in turn affects the degree of belief about whether or not the event had taken place.

This is not to say that there is a way of quantifying the evidence tendered in court to prove a case, but that the effect the evidence has on the belief of the fact-finder before a decision is made is critical. Still, the inherently more-likely-than-others approach established by Lord Nicholls in $\mathrm{Re} H$ has the effect of applying to all types of civil cases ranging from a typical civil case to a serious civil case. This 'catchall' application propounded by Lord Nicholls reflects an easy approach to dealing with all types of civil cases without actually taking into account the fact that seriousness of cases is subjective and varied. It is argued in this paper that the approach in $\mathrm{R} e H$ (i.e. the inherently more-likely-than-not test) is fundamentally flawed due to what happens when a serious case has facts that are rare and unique. Lord Nicholls suggests that the more serious the allegation, the less likely it is that the event occurred and, hence, the stronger the evidence should be. This means stronger evidence is required to satisfy a civil tribunal that the 'rare' allegation had indeed taken place. Although Lord Nicholls did recognise that some things are inherently more likely than others, ${ }^{62}$ it is difficult to understand how a serious civil case can be decided on a standard of balance of probabilities. The need for stronger evidence means that the weight of the evidence tendered in court must be very persuasive (or convincing) - persuasive enough (or convincing enough) to move the fact-finder to decide that the fact had occurred or existed.

$59 \operatorname{Re} B(\mathrm{n} 7) 35$.

60 For example, in insurance fraud cases, insurers avoid pleading fraud as the explanations and approaches used by judges indicate a different standard from the balance of probabilities standard: see, Johanna Hjalmarsson, 'The Standard of Proof in Civil Cases: An Insurance Fraud Perspective' (2013) IJE and P 47-73.

61 Redmayne (n 3) 169.

$62 \operatorname{Re} H(\mathrm{n} 33) 586$. 


\section{(E) CONFUSION ON STANDARD OF PROOF IN SERIOUS CIVIL CASES LEADING TO APPEALS}

A further problem with these confusing approaches is that they have led to appeals to the higher courts. For example, in $\mathrm{Re} D$, the Court of Appeal applied the flexible standard, and this was the main subject of appeal to the House of Lords. Although appeal courts rarely interfere with the findings of the trial judges, it is important for the parties and their lawyers to be aware of the relevant standard of proof that is applied to manage the case in the most effective manner. ${ }^{63}$ Confusing language describing the standard of proof in serious civil cases, such as that used by the Court of Appeal in Re D requiring 'more cogent evidence than would be conventionally required' and a 'more compelling quality of evidence' can, and (it is submitted) should, be avoided, and a more concise intermediate standard of proof applied for serious civil cases, as demonstrated in America. ${ }^{64}$

Similarly, in the recent case of $\operatorname{Re} S-B$ Children (Care Proceedings: Standard of Proof), the trial judge applied the standard which was not akin to the balance of probabilities in a childcare/placement proceeding and, during the fact-finding hearing, stated that there was a 60 per cent likelihood that the father had caused the injuries and 40 per cent chance of the mother having done so. ${ }^{65}$ The trial judge also proceeded to say: 'The allegations in this case are very serious ... When I apply the appropriate standard of proof, it has to be based on evidence of reliability and cogency equivalent to the gravity of the allegations.' ${ }^{\prime 6}$ Further, in $\mathrm{R}$ (McCann) v Crown Court at Manchester, Lord Steyn cited a passage in $\mathrm{Re} \mathrm{H}^{67}$ as authority that a higher standard should be applied in serious civil cases. These cases, in which the party appealed on the grounds of the application of the incorrect standard, demonstrate that the law in this area is still not clear and is indeed muddled by difficult language.

All the cases discussed in this section reinforce the rationale in $\mathrm{Re} H$ (with the exception of Bater) that the requirement for cogent evidence or careful scrutiny in fact does not affect the degree of probability. Thus, the balance of probabilities standard still applies in serious civil cases. But it is argued here that the requirement for cogent evidence and careful scrutiny in fact does affect the standard of proof. ${ }^{68}$ The analysis of the cases illustrates a policy decision by the courts and Parliament underlying certain civil cases (quite apart from special and hybrid civil cases) where a higher standard and a criminal standard have been applied.

\section{2 'Special' civil cases and hybrid cases justify the incorporation of an intermediate standard of proof}

Established 'special' civil cases that apply a standard higher than the balance of probabilities include actions of rectification that require the evidence to be 'strong and irrefragable'; 69 professional misconduct cases ${ }^{70}$ where intention to change domiciles must be 'clearly and unequivocally proved'; ${ }^{71}$ standards in determining paternity that are said to be higher than

63 Pattenden (n 14) 233.

$64 \operatorname{Re} D$ (n 9).

65 Re S-B Children (Care Proceedings: Standard of Proof) [2010] AC 678.

66 Ibid.

67 Re $H$ (n 33) 586.

68 C R Williams, 'Burdens and Standards in Civil Litigation' (2003) 25 Sydney Law Review 165-88, 185.

69 Re Snowden, Smith v Spourage [1979] 2 All ER 172, 177; Earl v Hector Whaling [1961] 1 Lloyd's Rep 459 (CA). See, also, R Cross and C Tapper, Cross on Evidence (6th edn Butterworths 1985) 149.

70 Rowland v Boyle [2003] EWHC 78 (Ch).

71 Moorbouse v Lord [1863] 10 HL Cas 272, 286. 
the civil standards but lower than the criminal standard $;^{72}$ the presumption that a marriage ceremony is valid, which requires evidence in rebuttal that is 'strong, distinct and satisfactory' 73 or 'evidence which satisfied beyond reasonable doubt that there was no valid marriage'; $; 4$ and the approval of medical treatment for an incompetent mentally ill patient, in which the proposed treatment must be 'convincingly shown' as medically necessary. ${ }^{75}$ In rectification cases and whether a secret trust exists, for example, ordinarily the standard of proof is balance of probabilities, however, where fraud is alleged, a higher standard of proof is required. ${ }^{76}$ Similarly, in enforcement actions under the Competition Act 1998, the Competition Appeal Tribunal (CAT) recognised that the Office of Fair Trading (OFT) has to discharge its burden of proof by adducing 'strong and compelling evidence' to prove that infringement had taken place and, given the seriousness of the allegations, the OFT will be required to exercise 'any reasonable doubt' in favour of the company being investigated. ${ }^{77}$ Further, the tribunal should not be anything less than sure that the decision was soundly based. ${ }^{78}$ Despite the CAT recognising $R e H$ and the civil standard, the CAT itself recognised that the test it was applying was tantamount to that of a criminal case. ${ }^{79}$ In $J J B$, the CAT stated that the evidence to prove infringement of the Act must be correspondingly more 'cogent'. ${ }^{80}$ It is observed from these cases involving infringement of the Competition Act that the CAT is trying very hard to reconcile and 'fit in' with Re H's interpretation of the civil standard. This is, in particular, quite astounding as numerous times in the judgments in Napp and $J J B$ the tribunal observes the gravity of the infringement and the corresponding need for evidence. In Yeganeh $v$ Zurich, ${ }^{81}$ the Court of Appeal appeared to apply a higher standard of proof (by looking for a reasonable doubt synonymous to the criminal standard) and found the allegation of arson unproven and decided that the trial court had failed to direct itself to the seriousness of the allegation (arson). The court did not designate any standard of proof, nor did it discuss any of the precedent found in section 1 of this article.

Given this wide range of the examples, it is evident that there will be a wide disparity of treatment in civil cases. The type of standard used depends on the facts of the individual cases. In these examples, it is difficult to understand why serious civil cases (especially those discussed in section 1) do not merit the same treatment. At the same time, it is difficult to comprehend why, in these cases, the courts have accepted a separate treatment of the standard from that adopted in serious civil cases. Although the courts have not labelled this as a separate standard from the civil standard, there is a tacit agreement that the standard in these cases is higher than the civil standard of balance of probabilities based on the nature of the cases.

$72 W v$ K [1988] Fam Law 64. See also Serio v Serio (n 19) above, the Court of Appeal held that the standard on the issue of paternity is slightly higher than the balance of probabilities.

73 Piers v Piers [1849] 2 HL Cas 331, 389.

74 Mahadervan v Mahadervan [1964] P 233, 246.

$75 \mathrm{R}(\mathrm{N})$ v $\operatorname{Dr} M[2003] 1$ WLR 562 (CA).

76 Re Snowden (n 69).

77 Napp Pharmaceutical Holdings Limited v DGFT [2002] CAT 1 [100]; Genzyme Limited v OFT [2004] CAT 4 [148]. See also JJB Sports plc v OFT and Allsports Limited v OFT [2004] CAT 17 [164].

78 Napp (n 77) [108].

79 Ibid [108].

$80 J J B(\mathrm{n}$ 77) [201].

81 Yeganeh v Zurich [2011] EWCA Civ 398. This case involved a claim made by Yeganeh of his household insurance policy in respect of the loss and damage to his property and its contents caused by a fire at the property. Zurich avoided the policy on the grounds both that the appellant had started the fire deliberately and also that he had knowingly made a false claim for the loss of items of his clothing. 
It is also difficult to understand why the same reasons used to reject the use of an intermediate standard in cases discussed in section 1 are not shared in these special cases. Common to these special cases is the fact that a definition of the higher standard of proof is typically lacking; instead, the mere statement that the standard is higher than the civil standard but lower than the criminal standard is made. In addition, the justification for a different standard for these special cases against the cases discussed in section 4 is not strong, especially in cases where the livelihood of the person alleged in the accusation is in question. A good example of the further development of this disparity of treatment is the implementation of hybrid cases.

The hybrid case is another category of civil case in which a different standard is applied - a criminal standard. Although a civil case is initiated in the civil court, applying Civil Procedure Rules (CPR) due to the consequence of the allegation could affect the livelihood of the defendant, so the standard is the criminal standard beyond reasonable doubt. A person who fails in establishing their defence in a civil case could be penalised and their movement restrained, clearly affecting their rights given by Article 8 of the European Convention on Human Rights, and resulting in moral stigma attached to the person through, for example, the loss of reputation, liberty and/or livelihood. Examples of such cases include: antisocial behaviour orders as found in s 1(1)(a) of the Crime and Disorder Act 1998; 82 applications involving sex offenders pursuant to s 2 of the Crime and Disorder Act 1998; 83 football banning orders pursuant to the Football Disorder Act 2000;84 and contempt proceedings. 85

Al-Khawaja, ${ }^{86}$ which dealt with detention pending deportation of persons alleged to be illegal immigrants, affords another illustration. In this case, if the allegation was found to be true on a balance of probabilities, the immigrant could be ordered to be deported. Such a deportation order can obviously be detrimental to the immigrant's liberty and livelihood. The decision of the House of Lords and the applicable standard of proof was unclear. The House of Lords seemed to apply the civil standard of balance of probabilities on the defendants to prove that they entered into the country legally and imposed a higher standard on the government to prove that the immigrants had entered into the country unlawfully. ${ }^{87}$ Further, Lord Scarman's expression that the facts justifying detention must be proved 'to the satisfaction of the court' seemed to connote a higher standard of proof. 88 Conversely, in Secretary of State for the Home Department $v$ Rehman, a case concerning deportation on the grounds of alleged links to terrorism, where the House of Lords ruled that while any specific facts on which the Secretary of State relied should be proved on the ordinary civil balance of probability, no particular standard of proof was appropriate to the formation of his executive judgment or assessment as to whether it was conducive to the public good that a person should be deported, which was simply a matter of a reasonable and proportionate judgment on the material before him. ${ }^{89}$ The concern is that, despite the fact that both Khawaja and Rehman are cases dealing with deportation, in practice, the courts treat them differently from each other - a higher standard of proof is mandated in the

$82 \mathrm{R}$ (McCann) (n 21).

83 B v Chief Constable of Avon and Somerset Constabulary [2001] 1 WLR 340.

84 Gough v Chief Constable of the Derbyshire Constabulary [2002] QB 1213 (HC).

85 Re Bramblevale Ltd [1970] Ch 128.

86 Al-Khawaja (n 8).

87 Ibid 777, 784, 791, 794.

88 Ibid 784; the standard of proof imposed on the government was higher than that which the applicants had to satisfy, per Lord Fraser, 772 (HL). See also Pattenden (n 14) 222.

89 Secretary for State for the Home Department v Rehman [2003] 1 AC 153: cf Al-Khawaja (n 8). 
former, whilst the latter does not require a particular standard (even that of balance of probabilities), irrespective of the seriousness of the consequence. ${ }^{90}$

There are various other cases where, for policy reasons, judges must carefully scrutinise the evidence presented in court; for example, in asylum and immigration cases or other matters affecting human rights (as seen above), including judicial review applications. This is consistent with the justification for applying an intermediate standard in serious civil cases in America. It is suggested that these cases could benefit from an intermediate standard, as opposed to the balance of probabilities standard. Once more, it is argued that the approach that the courts currently use is laden with confusing language that produces incoherence.

\section{Intermediate standard of proof in USA}

A third standard of proof is accepted in the USA - namely that of clear and convincing evidence (much more likely than not) - as an intermediate standard of proof between the balance of probabilities and beyond reasonable doubt. This standard is aimed at addressing the inconsistencies produced by using the traditional balance of probabilities standard. ${ }^{91}$ The higher standard was also introduced to address issues that involve 'fundamental constitutional rights' when the individual 'interests at stake' are both particularly important and more substantial than 'mere loss of money'. ${ }^{92}$ The standard is reflected on the degree of confidence American society thinks the fact-finder should have in the correctness of the factual conclusions for a particular type of adjudication. This is why the highest proof beyond a reasonable doubt - is required in criminal cases. The standard is defined as that measure or degree of proof that will produce in the mind of the juror a firm belief or conviction as to the truth of the allegations sought to be established. ${ }^{93}$ (This is argued in this paper to be the standard in serious civil cases in England and Wales as seen in section 1.) This is also argued to be less problematic in England and Wales, as jury members are only found in a minority of civil cases. ${ }^{94}$

In the US, the court would apply a three-part test to determine the imposition of the intermediate standard on a particular case: ${ }^{95}$

(i) The private interests affected by the judicial proceeding - if the individual "may be "condemned to suffer grievous loss"" by the action of the state, and if "the loss threatened by the particular proceeding is sufficiently grave to warrant more than average certainty on the part of the fact finder [because of] both the nature of the private interest threatened and the permanency of the threatened loss'. ${ }^{96}$ A party will have to demonstrate that a deprivation of a fundamental right is at stake and, further, a deprivation of a private interest can be final and irrevocable.

(ii) The risk of error created by the state's chosen procedure or that the judicial process has a high risk of erroneous fact-finding, and

90 See Woodby v Immigration and Naturalisation Service 385 US 276 (1966), the Supreme Court took into account similar considerations of deporting a person from the country, similar to Al-Khawaja (n 8). However, unlike, Al-Khawaja, the US Supreme Court applied a fixed intermediate standard of proof.

91 McCormick (n 22) 441-45.

92 Justice Bill Valance, 'The Clear and Convincing Evidence Standard in Texas: A Critique' (1996) 48 Baylor Law Review 391.

93 14th Amendment to the US Constitution.

94 Addington v Texas 441 US 418 (1979). See also Re Winship 897 US 358, 370, 90 S Ct 1068, 1076, 25 L Ed 2d 368 (1970).

95 Mathews v Eldridge 424 US 319, 335 (1976).

96 Santosky v Kramer 455 US, 758 (1982). 
(iii) The court will evaluate the countervailing governmental interest that would be served by the use of a lower preponderance of the evidence standard. Unless, the use of the lower standard is so strong as to be compelling, the intermediate standard will not be required. ${ }^{97}$

The Supreme Court in deciding whether to impose the intermediate standard would also look at the practice of the states and the common law tradition and their underlying values in certain sets of facts. ${ }^{98}$ The intermediate standard serves to allocate the risk of error between the litigants and to indicate the relative importance attached to the ultimate decision. ${ }^{99}$ The standard of proof (at a minimum) reflects the value society places on individual liberty. 100 The function of legal process is to minimise the risk of erroneous decision. ${ }^{101}$ Burger CJ in the US Supreme Court case of Addington $v$ Texas stated that the intermediate standard is typically used in civil cases involving allegations of fraud or deception and other 'quasi-criminal wrongdoing'. ${ }^{102}$ The case of Addington concerned the involuntary commitment of an individual for an indefinite period to a state mental hospital; the US Supreme Court had to consider what standard of proof was required by the 14th Amendment to the US Constitution based on these facts. ${ }^{103}$ It was decided that the intermediate standard of proof applied, as the individual's liberty was potentially affected by him being committed indefinitely, and is compared against the state's interests in providing care for the individual and in protecting the community from the dangerous tendencies of some who are mentally ill; thus, due process requires the state to justify confinement. ${ }^{104}$ This approach has been commonly applied in cases involving denaturalisation, ${ }^{105}$ termination of parental rights, ${ }^{106}$ deportation, ${ }^{107}$ paternity determining, ${ }^{108}$ defamation ${ }^{109}$ and civil commitment to a mental hospital. ${ }^{110}$ Still, the range of cases varies from state to state, each of which has its own policies. ${ }^{111}$ The standard is also applied in the following cases: fraud; undue influence; existence or contents of a lost deed or will, parol gift or agreement to bequeath by will; mistake sufficient to reform an instrument; parol or constructive trust; oral contract as a basis for specific performance; anticipatory use of an invention; and whether a deed absolute is a mortgage. ${ }^{112}$

The standard is typically set to $67-75$ per cent probability, higher than the civil standard of balance of probabilities, mathematically quantified at 50 per cent +1 in a typical civil

97 Santosky v Kramer (n 96) 745. See, Cruzan v Director, Missouri Department of Health 110 S Ct 2841 (1990), where an intermediate standard was imposed in a case for an unconscious person to withdraw life-sustaining treatment and the court observed that the state applied this standard to protect the individual's interests and, subsequently, against unwarranted state action.

98 Michael H v Gerald D 491 US 110 (1989).

99 Addington $v$ Texas (n 94).

100 Tippett v Maryland 436 F 2d 1158, 1166.

101 See Mathews v Eldridge 424 US 319, 335, 96 S Ct 893, 903.

102441 US 418 (1979).

103 14th Amendment to the US Constitution.

104 Addington $v$ Texas (n 94).

105 Nishikawa v Dulles 356 US 129 (1958).

106 Santosky v Kramer (n 96) 745.

107 Woodby $v$ Immigration and Naturalisation Service 385 US 276 (1966).

108 Brown $v$ Edwards Transfer Co 764 SW 2d 220 (Tex1988).

109 Casso v Brand 776 SW 2d 551, 552-53 (Tex 1989).

110 Addington $v$ Texas (n 94).

111 McCormick (n 22) 516.

112 John Henry Wigmore, Evidence in Trials at Common Law (3rd edn Little, Brown 1940) 329. 
case. ${ }^{113}$ The US Supreme Court in Addington accepted the difficulty of quantifying exactly how much evidence is required in serious civil cases when the intermediate standard is applied; however, it saw the third standard as also having an important communicative function. ${ }^{114}$ It reminded fact-finders that, owing to the seriousness of what is alleged or what is at stake, the need for careful deliberation becomes necessary. This means the risks of error in decision-making are not to be distributed more or less equally between the parties, which is the function performed by the normal balance of probabilities. Similarly, the third standard reminds the fact-finder that the error in decision-making is not as high as the criminal standard, as it does not involve punishing the offender.

This is a much clearer approach than the current approach used by the English courts. Applying probability judgments in mathematical terms (as seen above) can be very useful in trying to minimise the risk of errors (and to improve human processes, i.e. fact-finding considerations) in serious civil cases based on the reasoning given by Burger $\mathrm{CJ}$ in Addington above. In addition, explaining to the jury the standard being the highest standard in civil cases will demonstrate the significance of the interests at stake and is probably easier to explain to a jury than a floating standard or asking for more 'cogent evidence' or applying the 'anxious scrutiny' test ${ }^{115}$ (see below in section 5).

\section{The reluctance of the judiciary to adopt an intermediate standard of proof}

The primary justification to explain the judges' reluctance in England and Wales perhaps stems from the dangers of imposing a higher standard of proof in a civil case. ${ }^{116}$ This is evident in care proceedings, of which $\operatorname{Re} B$ is an excellent example, whereby a care order application was filed on the basis of a reported sexual abuse of a child by a step-parent. $\operatorname{Re} B$ affirms the decision in $\mathrm{Re} H$ that the standard of proof in respect of the threshold criteria in s 31(2) of the Children Act 1989 is the balance of probabilities. The same standard was said to apply in the welfare considerations provision of $\mathrm{s} 1$ of the same Act, affirming $\operatorname{Re} U .^{117}$

Although Baroness Hale accepted that some civil cases do require the criminal standard of proof and gave examples, including Bater $v$ Bater, she did not hold that care proceedings required this higher standard. She asserted that the primary intention is always to protect the child from harm, rather than to deter or punish the person against whom the allegation is made. ${ }^{118}$ The rationale is that, if a higher standard is adopted, then it may be difficult for the allegation to be made out by the local authorities.

Despite the facts that the law values a family home and envisages avoiding unjustified interventions in the family home, as evident in the threshold in s 31 of the Children Act 1989, ${ }^{119}$ and a child wrongly removed may be damaged for life, ${ }^{120}$ a higher standard of proof could effectively reduce the likelihood of an application being granted for the child to be removed from the home. As a result, the child may suffer significant harm by

113 McCormick (n 22). See also United States v Fatico 458 F Supp 388 (EDNY) (1978).

114 McCormick (n 22).

115 D Hagman and M MacArthur, 'Evidence: The Validity of Multiple Standards of Proof' (1959) Wisconsin Law Review 525, 538-40.

116 Baroness Hale's response, in $\operatorname{Re} B$ (n 7) 22, that the law in this area had been authoritatively determined compelled her to observe that 'it is time for us to loosen its grip and give it its quietus' is an example of this reluctance.

$117 \operatorname{Re} U$ (A Child) [2004] EWCA Civ 567.

$118 \operatorname{Re} B(\mathrm{n} 7) 22$ [69].

119 See also Article 8 of the European Convention of Human Rights or Human Rights Act 1998.

120 See $R v$ C [2007] EWCA Crim 2551. 
remaining in the same household with the abusive or neglecting parent. ${ }^{121}$ Lord Lloyd stated that the standard should remain the civil standard. Lord Lloyd based his views mainly on the threshold criteria stating that, if it was a higher standard, then the court will not be able to go on and consider the checklist in s 1(3) of the Children Act 1989, however grave the anticipated injury is to the child. ${ }^{122}$ This view is perhaps justified, as there is less risk to the parent than to the child when the balance of probabilities remains the civil standard rather than a higher standard of proof; after all, in family law, the child's interest is of paramount consideration addressing the welfare principle in $\mathrm{s} 1$ and the threshold criteria found in s 31(2) of the Children Act of 1989.123

The cases of Baby $\mathrm{P}^{124}$ Chelsea Brown ${ }^{125}$ and Anna Climbié ${ }^{126}$ provide effective evidence to support the contention that the standard should remain at the balance of probabilities. ${ }^{127}$ They illustrate the threat of resulting death of children who suffer abuse at home. Baroness Hale referred to Dame Elizabeth Butler-Sloss in her judgment in $R v$ Cannings when her Ladyship stated that there was no good reason in addressing issues relating to a crime, and that preventive measures should be taken to restrain defendants for the benefit of the community, and for that of child protection and child welfare. ${ }^{128}$ It is argued in this paper that Parliament's intention is clear, following the threshold criteria and the welfare principle, that the child's interests are paramount and the legitimate concerns of the state must be upheld. It is also argued in this paper that a third standard of proof is not appropriate in child protection or child welfare matters due to the strong cultural features of protecting children from harm found in England and Wales.

For that reason, it is argued in this paper that the decision made in $R e B$ is correct based on the facts presented therein. Although this decision not to include child protection matters in the list of cases when the intermediate standard of proof applies, as is done in America, the final decision lies on the individual state and its concerns with specific crimes.

The second possible justification for the reluctance in introducing an intermediate standard of proof would be the risk of causing confusion and uncertainty, not only to the members of the judiciary, but also to lawyers advising their clients. For example, Lord Nicholls in $R e H$ rejected the use of a third standard of proof:

The only alternative which suggests itself is that the standard should be commensurate with the gravity of the allegation and the seriousness of the consequences. A formula to this effect has its attraction. But I doubt whether in practice it would add much to the present test in civil cases, and it would risk causing confusion and uncertainty. 129

121 John R Spencer, 'Evidence in Child Abuse Cases: Too High a Price for Too High a Standard?’ (1994) 6 JCL 160.

$122 \mathrm{Re} H$ (n 33) 577.

123 Children Act 1989, s 1(1).

124 R v B [2010] EWCA Crim 4. See also <www.bbc.co.uk/news/education-11621391> accessed 15 September 2012.

125 <http://news.bbc.co.uk/2/hi/uk_news/1206019.stm> accessed 15 September, 2012.

$126 \mathrm{R}$ (On the Application of Shoesmith) $v$ Ofsted [2011] PTSR D13. See also <http://news.bbc.co.uk/ 2/hi/uk_news/1114298.stm> accessed 15 September 2012.

127 In March 2011, the NSPCC stated that approximately 46,700 children were known to be at risk of child abuse at the time, see <www.nspcc.org.uk/Inform/research/statistics/prevalence_and_incidence_ of_child_abuse_and_neglect_wda48740.html > accessed 15 September 2012. After Baby P's death, the number of care orders applied for reached a record high: see <www.guardian.co.uk/society/ 2011/sep/08/baby-p-effect-child-protection> accessed 9 September 2012. This policy reasoning could explain the reluctance in applying a higher standard to serious civil cases.

128 R $v$ Canning [2004] 1 WLR 2607.

$129 \operatorname{Re} H($ n 33) 587. 
It is argued that this matter has not been effectively investigated, for whilst 'special' civil cases and hybrid cases are recognised as requiring a higher standard, the same is not extended to other serious civil cases discussed in section 1. The reluctance to do so may relate to the difficulty of identifying the type of cases that should be included in this category, combined with the difficulty of justifying one particular fact or case over another. ${ }^{130}$

As argued in this paper, the current position of serious civil cases could be stabilised by identifying a range of clear cases to which an intermediate standard of proof could be applied. This approach would set in motion a process of incremental development. However, it would be clearer than the law as it now stands and mark a significant advance over the confusion and uncertainty that has prevailed for too long.

\section{A proposal for reform}

It is suggested that Parliament should set up a CPR Committee in consultation with members of the judiciary with the task of considering which of the serious civil cases mandate an intermediate standard, as was done in hybrid cases (see in section 2 above). It may be that similar cases identified in America can also be identified here, which might warrant an intermediate standard of proof. Particular importance is drawn from the threestage test utilised in America in deciding if a particular set of facts warrant a higher standard of proof based on the interests at stake against that of the state (see section 3). Some might argue that the American approach of an intermediate standard is pegged to the American Constitution; this does not mean a similar approach cannot be applied in England and Wales. A process of incrementally developing the list must be kept under review.

The reason why it is proposed that only a selection of serious civil cases be considered is because there are certain cases - in particular, child protection proceedings - when a higher standard may subject the child to further harm, as discussed in section $4 .{ }^{131}$ The list should also contain cases that would affect the liberty and livelihood of the party in the civil action. These would include deportation cases, ${ }^{132}$ civil commitment to a mental hospital, declining to recommend the release of a prisoner, or, in other words, any case that has the consequence of influencing the loss of the liberty of an individual. ${ }^{133}$ From the suggestion above, this is not to say that the list contains only cases that carry a serious consequence, but the list must be open to include any serious civil case that might also carry a serious allegation. An example of this is when fraud and criminal accusations affect the livelihood and liberty of an individual in the community.

In America, the formulation for jury instructions which a judge might give on the appropriate standard of proof varies from state to state. A clear specimen direction should be issued for judges in England and Wales when explaining the intermediate standard of proof to the parties in the proceedings. It is suggested in this paper that the following could

130 See Pattenden (n 14) 232, who states that a third standard of proof is the best solution to serious civil cases. See also Lord Nicholls, in Re H (n 29) 587, expressing the difficulty in identifying what the standard is and when it applies. See also Ian Dennis, The Law of Evidence (4th edn Sweet \& Maxwell2008) 398, where Dennis stated that the argument for not incorporating a third standard was not entirely persuasive. He also added that the rejection of a third standard was 'over-hasty'.

131 See Lord Nicholls in Re H (n 33) 587; Lord Lloyd, Re H (n 33) 577; Baroness Hale in Re B (n 7); Dame ButlerSloss in $\mathrm{R} v$ Canning (n 128). Similarly, Articles 2 and 3 of the European Court of Human Rights that the child has the right to life and not to be subjected to torture, inhuman and degrading treatment.

132 Al-Khawaja (n 8).

133 Rebman (n 89). 
be applied in English courts (a combination of the definition applied in Federal courts and in Kansas and Colorado): 134

proof which is stronger than a balance of probabilities and which is clear in the sense that it is certain, plain to the understanding, unambiguous, and convincing in the sense that it is so persuasive as to cause you to believe it . . . This standard is the highest civil standard, sitting between the balance of probabilities and the criminal standard of beyond reasonable doubt - higher than the balance of probabilities, but lower than the criminal standard. [Mathematical quantifications to follow.]

In addition to the above definition, to avoid any uncertainty or confusion when applying a third standard of proof, it may be necessary to quantify to the parties in the civil proceedings the different standards of proof - i.e. the civil standard, the intermediate standard and the criminal standard. Kagehiro conducted a study on the understanding of fact-finders when they are provided with a legal definition and a quantified definition to determine whether the applicable standard in any given case achieves the law's professed goal of appropriately distributing the risk of erroneous decision-making. ${ }^{135}$ Based on the research, Kagehiro argues that a relationship between the standard of proof and risk of erroneous decision-making be demonstrated and this may be done in a comparative context. The study also indicates that quantification of standard of proof merely makes explicit what is implicit in the original legal definition and concludes that quantified definitions could function as yardsticks against which the legal definition is measured.136 This will clarify the need to meet the intended standard and the evidence required to establish the necessary facts according to the relevant standards, as compared to merely providing legal (unquantified) definitions. ${ }^{137}$ The judge would decide if the intermediate standard has been met in a particular case. The judge can direct jury members to both the criminal and civil standards and explain to them how the intermediate standard sits in between both these standards. Again, in very limited and exceptional circumstances does a jury sit in civil cases in England and Wales, a factor which should encourage Parliament to include an intermediate standard in serious civil cases. ${ }^{138}$ Further to the suggested legal direction above, the judge could include a quantified direction to assist in the decisionmaking and to avoid risk of erroneous decisions. The suggested mathematical quantification for this standard is set to $67-75$ per cent probability. ${ }^{139}$

134 See, also, Mason v Texaco Inc 741 F Supp, 1510.

135 D K Kagehiro and W C Stanton, 'Legal vs. Quantified Definitions of Standards of Proof' (1985) 9 Law and Human Behaviour 159-78, 171-76.

136 If there is an assumption of calculated risk in the guilt determination process expressed in a quantified definition, it is because the assumption of risk is present in the original legal definition, see, John Kaplan, 'Decision Theory and the Factfinding Process' (1968) 20 Stanford Law Review, 1065-92.

137 Kagehiro and Stanton (n 135) 161.

138 Heydon's argument in J Heydon, Evidence Cases and Materials (2nd edn Butterworth 1984) 36, that the adoption of a third standard of proof would make jury direction even harder than it is at present with two. Rosemary Pattenden, see (n 14) 229, counter-argues Heydon's comment stating that a third standard of proof is easier to explain to a jury than a floating standard which requires a higher quantum of proof for serious civil cases. See, also, a similar argument put forward by D Hagman and M MacArthur (n 115) 538-40.

139 Jeremy Bentham in Rationale of Evidence, Book I, ch 6, advocated applying a numerical scale for defining the third standard of proof due to the incapacity of ordinary language to define the degree of probabilities and the probative force: The Works of Jeremy Bentham, John Bowring (ed) (London 1838-1843, reprinted New York 1962) vol 6, An Introductory View of the Rationale of Evidence; Rationale of Judicial Evidence, specially applied to English Practice, Books I-IV. 
Moreover, although there can never be absolute certainty in the decision-making process, it would be easier if judges were aware of the complexity of the case before them, including best evidence, and conscious of the ramifications of the case before deciding on whether the allegation is true or not. This could be achieved at the case management stage.

\section{Conclusion}

Judges have applied various approaches in explaining what the standard of proof actually is in serious civil cases which have contributed to incoherence in the law. This incoherence is due to the choice of language used to describe the standard of proof in serious civil cases. This language seems to suggest a different standard from the civil standard of the normal balance of probabilities. Language applied in each of the cases discussed in section 1 above seems to suggest a standard different from the normal balance of probabilities. The requirement for more cogent evidence and caution in serious civil cases establishes a different standard altogether from the normal balance of probabilities standard applied in civil cases. An intermediate standard is suggested as a possible solution. This is especially relevant given that, in other 'special' civil cases and hybrid cases, a higher standard of proof than the civil standard is required. It is difficult to appreciate why there is a disparity in treatment between these cases and serious civil cases. The courts have remained reluctant to permit and apply an intermediate standard, even though it is evident that the incoherence of the law justifies some changes. The judiciary may have good reasons for its reluctance in permitting a higher standard of proof in cases dealing with, for instance, children faced with harm from an abusive or neglecting parent, since setting a standard too high could result in more harm to the child than when the standard is lower. This does not mean that we should be deterred from considering other cases in the list when an intermediate standard is applied. Childcare cases will be an exception.

As in America, a list of cases can be identified by Parliament through the auspices of a commission when the intermediate standard is applied, especially since this has already been done in 'special' civil cases. It is accepted that the judicial system cannot always mandate absolute accuracy in its findings of the evidence presented. However, the need to reflect coherence and minimal error far outweighs the need to apply the civil standard of balance of probabilities found in England and Wales. The current non-exhaustive list should be reviewed once every two years. Whether or not an intermediate standard is introduced, as seen in America, a proper procedure to address the standard of proof in serious civil cases in a consistent and coherent manner is needed to clarify the law of evidence. Judges should become more conscious of the ramifications of the arguments that they make concerning the interpretation of language, and should move to accept that we are better off with a third standard of proof in serious cases, rather than leaving it to the good sense and better judgment of an individual judge. The criminal standard, for instance, is well understood now, despite the difficulty the courts faced in explaining what a reasonable doubt is. ${ }^{140}$

In conclusion, the advantages of applying an intermediate standard in serious civil cases may be summarised as follows:

$i$ it would potentially remove the confusion and incoherence that the current system presents, mainly addressing the choice of language used in describing the standard of proof;

ii it would ensure that parties initiating appeals on grounds that the trial judge had applied the wrong approach might be avoided;

140 R v Ching [1976] 63 Cr App R 7, 9; R v Gray [1974] 58 Cr App R 117. 
iii most civil cases in England and Wales do not have jury members presiding over them, hence any technical difficulty or legal jargon used by the judges in explaining the proceedings concerning the relevant standard of proof in serious civil cases may present less of a challenge;

iv the 'special' cases listed in section 2 are proof of the inconsistent use of the civil standard of proof, and perhaps including them in the same list as a selected few serious civil cases, when an intermediate standard of proof is used, would ensure more consistency in the civil justice system. 